\title{
Offline Support Model for Low Bandwidth Users to Survive in MOOCs
}

\author{
https://doi.org/10.3991/ijet.v13i10.8595 \\ Laxmisha Rai \\ Shandong University of Science and Technology, Qingdao, China \\ laxmisha@ieee.org
}

\begin{abstract}
To access MOOCs'(Massive Open Online Courses) contents, and complete them successfully, resources such as computers or smart phones, Internet access with high-bandwidth are highly essential. Moreover, other facilities such as power requirement for electronic devices and software tools to view the MOOC contents within the course duration are necessary to complete the assessments. This shows that, the students must remain with online access more than expected. This not only a major requirement for completion of MOOCs, but also hinder the progress of learning in low bandwidth regions, and also for learners with listening or visual disabilities. Considering all these, in this paper addresses three learner challenges related to MOOCs: (1) what are the methods of reducing usage of electronic devices during online learning?, (2) what are the possible measures for effective learning with limited online presence?, and (3) how to survive successful completion in low-bandwidth contexts. An offline support model is proposed to reduce the online presence during online learning and to manage the low-bandwidth challenges.
\end{abstract}

Keywords-MOOC, offline, online, learning, support model, electronic usage

\section{Introduction}

In recent years MOOCs' providers such as edX(ww.edx.org),Udacity (www.udacity.com),iVersity(www.iversity.org), FutureLearn (www.futurelearn.com), and Coursera (www.coursera.org) are getting worldwide attention from learners, teachers, educators, scholars, and policy makers making it as an optimistic trend especially in higher education. Explosion of MOOCs gave enthusiastic digital educators and learners to consider online learning seriously. Even though, the e-Learning, digital learning, and distance education concepts were few decades old, MOOCs from reputed universities around the world attracted such learners who were unable to acquire high-quality education easily in their home countries. Similarly, the online learning materials available in YouTube (www.YouTube.com) or Khan Academy (www.khanacademy.org) are also gained widespread attention among learners. The courses offered by MOOC providers such as edX, Stanford Online, iVersity, Coursera, and Udacity are usually taught by university professors, and leading experts in their specialized field. These courses 
are not only free, but also able to accommodate thousands of learners from different geographic regions, backgrounds and age groups.

Considering the example of edX, launched in May 2013 by MIT and Harvard to provide MOOCs on non-profit focuses on transforming online and on-campus learning through ground breaking methodologies such as with gamification and cutting-edge research on an open source platform [1]. This kind of initiative also created localized versions of MOOC providers around the world. As edX supports open source platform, several countries and institutions around the world started adopting this platform. For example, XuetangX initative in China, FUN (France UniversitéNumérique) in France, and Edraak in Arabic speaking regions. In addition, in 2016, NIIT, a skill and talent development company based in India entered strategic partnership with edX to redefine online education to boost future talents [2]. These developments show that, MOOCs are reaching every corner of the world, with considerable support and attention from local organizations. However, considering the success and failure of MOOC participants, the data available were shocking. According to data compiled in 2013, the average MOOC completion rate across the 29 courses was just $6.8 \%$ [3]. In another example, of the 841,687 students enrolled at Harvard and the MIT, only 5\% earned certificates [4].

The 2013 world population data forecasts world population will grow 9.7 billion in 2050, and population in 2013 is around 7.1 billion, where only 1.2 billion live in more developed countries, and 5.9 billion in less developed countries [5]. As per the 2016 International Telecommunications Union (ITU) report, $53 \%$ of the world's population - is not using the Internet, and in Africa alone, almost $75 \%$ of people are not using Internet [6]. These statistics shows the limitations of connecting to online contents, especially while accessing high-quality educational resources such as MOOCs. Earlier surveys suggest MOOCs are failing to educate the poor or disadvantaged [7]. Few researchers also identified the problems faced in developing countries with case study of Sri Lanka. Of the $42 \%$ of participant's in the survey, they identified common challenges were: infrastructure facilities (58\%), unavailability of skilled staff (51\%), and other reasons (29\%) [8]. Researchers are also investigated negative impact on MOOC learners in Africa because of low Internet bandwidth and other reasons such as limited access to computers, computer illiteracy, and electricity blackouts [9].

In this paper, the low bandwidth challenges faced by the learners especially from the developing world are listed, and an offline digital support model is proposed. The paper is organized as follows. In the Section 2 the existing infrastructure challenges faced by MOOC learners are presented, and Section 3 describes the specific challenges related to low bandwidth. The proposed offline support model for surviving in MOOCs is presented in Section 4 and finally Section 5 concludes the paper.

\section{General Infrastructure Challenges}

So, far, there are no specific hardware or software requirements defined by MOOCs providers. However, it is obvious that, students need a computer (or a smart device) and Internet connection to access these courses, as they are totally provided online. As 
Internet connection is basic requirement, one need devices such as desktop, laptop computer or similar devices with a browser to access the courses. Most of the MOOCs contents are delivered as video lectures. If the videos are available through YouTube streams, or through YouTube links, and if such videos (such as YouTube) blocked in a particular region, then learners are unable to view the video contents. In addition to computers, one may need speakers, microphones or cameras for successful completion of some of the MOOCs. For example, in a public speaking, or language learning courses, learners may need to record their speech as a homework submission for grading. Similarly, some instructors may ask to record a video of the learner to introduce themselves to the other peer learners. So, learners also need to have video or audio recording software to facilitate this. Some Computer Science, or Software related courses need the learners to download special software packages (such as virtual machines, compilers etc.), and install them on their own computers which may need additional software or hardware requirements. In case of a Harvard course, students are required to describe their final project, and submit as a video to the website. So, different courses may demand different hardware or software tools to successfully complete the course. The other aspect is about the dealing with technical problems. Sometimes, unexpected situations may lead to Internet breakdown, power failures, and hard-drive crash so on. The reasons could be server failures, network error, slow Internet, software installation errors or bad weather conditions. These kinds of problems may effect in both locations of MOOC providers as well as on learners. Most of these problems must be addressed by the learners, and the MOOC providers are usually not responsible for dealing with such technical issues.

\section{Low Bandwidth Challenges}

In the recent years, several researchers have identified the problems related lowbandwidth while accessing MOOC contents in addition to resource limitations, lack of funding, digital literacy level, and linguistic barriers etc. In [10] authors argued that, the proper access to computer and Internet with required bandwidth is essential for success in a MOOC platform. Similarly, problems related downloading learning contents discussed in [11]. The problems such as power outages, intermittent Internet connectivity and low-bandwidth considered as most common obstacles which discourage eLearning in several low-income countries. Considering this, researchers have focused attention on the course delivery methods and formats of course contents. For example, text-based and low-bandwidth contents were hosted on Moodle site instead of multimedia contents to support low-bandwidth connections considering the infrastructure limitations exist in developing countries [12]. Moreover, the transcripts and lecture slides are considered as a possible alternative to streaming videos[13]. Researchers in [14] mentioned about inequality of access of MOOC contents around the world and stressed the need of advanced data transfer methods in low and middle income countries. Serious constraints of bandwidth limitations, limitations of accessing live streaming videos are discussed in [15]. They have also suggested the home-grown model with 
emphasizing development of low-bandwidth intensive technologies such as delivering MOOC contents over instant messaging applications.

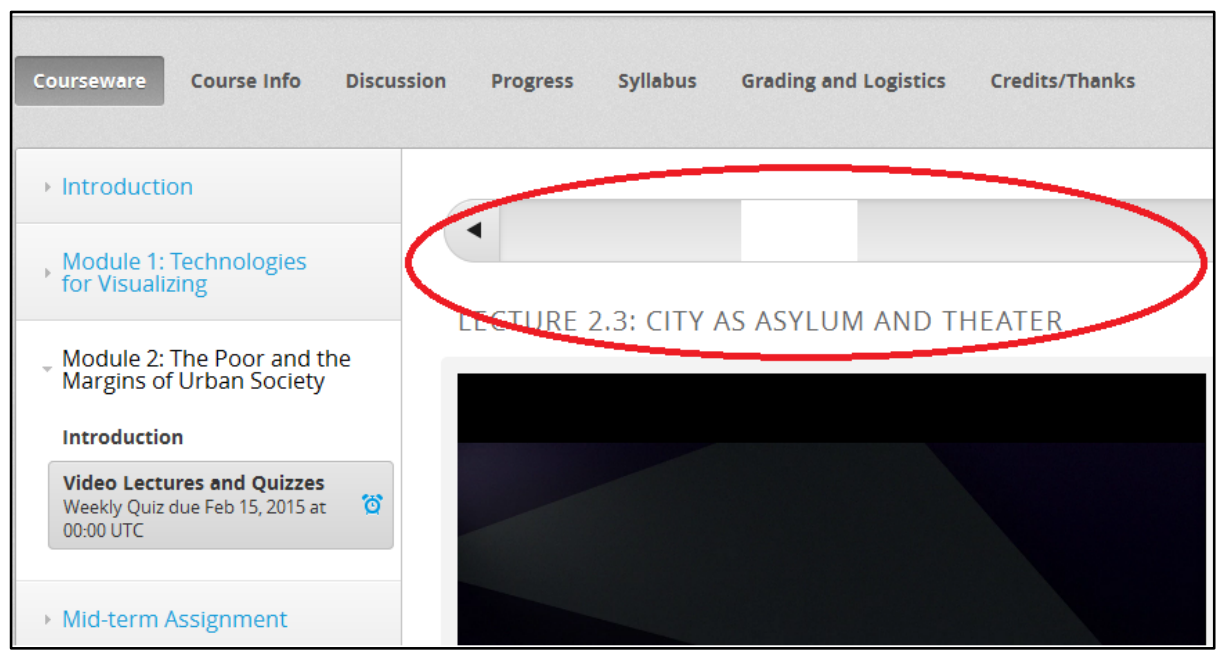

Fig. 1. Zero visibility of course progress bar page and course video.

Even though in some exceptional cases, learners may gather learning materials, however to complete the various assessments (as shown in Table 2), stable Internet connection is required. It is not uncommon that, in few cases because of partial visibility of learning material or assessments, probability of completing a MOOC successfully is lower. As shown in Fig. 1, the course video, and the progress bar contents are totally invisible (in case of an edX MOOC), and this may create a frustrating situation among online learners. Moreover in some cases, the learner is unable to verify the right or wrong answer while answering a multiple choice question (MCQ) as the animated feedback symbol is invisible due to low network speed. This also shows that, text and animated materials also slow to download while answering MOOC assignments online.

\section{$4 \quad$ Proposed Offline Support Model}

Today, the MOOC learning materials are delivered mostly using multimedia contents such as videos, audios, and images. These media contents are not only provide the feeling of real-classroom participation, but also provide quick assimilation of the course contents. However, it is hard to judge multimedia contents are always the best way to reach the learners around the world. With the existing learner limitations such as lowbandwidth, limited access to computers, and limited time to spend online, there are many learners find it difficult to cope with these challenges. Making courses completely online with less scope for offline learning is considered as one of the key weakness of existing MOOCs. In this paper we argue that, as the power breakdowns, and Internet limitations are common in MOOCs, it is recommended to bring the temporary solutions to survive MOOCs in the long-term. For example, providing MOOC interactive 
exercises in a single formatted downloadable text (with limited inclusion of images), not only save the data storage limitations and it will also provide a uniform repository for the future. Earlier researchers also found that, students who worked offline with someone else achieved better results than someone who totally worked online [16]. The Table 1 shows the general list of contents in most of the existing MOOCs offered by edX. Table 2 lists the general assessment methods in existing MOOCs. Moreover, some of these contents may have overlapped information. For example, the indices C16 to $\mathrm{C} 20$, and the assessment methods shows in Table 2 is part of Courseware heading. This list is gathered after successfully completing over 100 MOOCs (by the author) offered through edX between 2012 and 2017.

The Table 3 lists summary of MOOCs content and assessment accessibility methods in the current and the proposed model. However, this paper is not supporting the idea of removing video, audio materials or interactive exercises from MOOCs - which are the fundamental learning resources of MOOCs, rather the paper propose options for accessing the contents of same merit and value by spending less time online, and max-

Table 1. General learning contents and media types in existing MOOCs

\begin{tabular}{|c|c|}
\hline Ref. Index & Content Details \\
\hline $\mathrm{C} 1$ & About the Course \\
\hline $\mathrm{C} 2$ & Course Outline \\
\hline $\mathrm{C} 3$ & Course Info \\
\hline $\mathrm{C} 4$ & Course Syllabus \\
\hline $\mathrm{C} 5$ & Course Format \\
\hline C6 & Recommended Background \\
\hline $\mathrm{C} 7$ & Suggested Readings \\
\hline $\mathrm{C} 8$ & Textbooks \\
\hline C9 & Grading Scheme \\
\hline $\mathrm{C} 10$ & Resources \\
\hline $\mathrm{C} 11$ & Gallery \\
\hline $\mathrm{C} 12$ & Help \\
\hline $\mathrm{C} 13$ & Frequently Asked Questions(FAQs) \\
\hline $\mathrm{C} 14$ & Writing Resources \\
\hline $\mathrm{C} 15$ & Announcements \\
\hline $\mathrm{C} 16$ & Video Lectures \\
\hline $\mathrm{C} 17$ & Video Lecture Subtitles \\
\hline $\mathrm{C} 18$ & Audio Lectures \\
\hline $\mathrm{C} 19$ & Audio Lecture Subtitles \\
\hline $\mathrm{C} 20$ & PowerPoint Presentations/Handouts \\
\hline $\mathrm{C} 21$ & Progress Bar/Grades \\
\hline $\mathrm{C} 22$ & Learning Communities \\
\hline $\mathrm{C} 23$ & Discussions/Forums \\
\hline $\mathrm{C} 24$ & Glossary \\
\hline $\mathrm{C} 25$ & Wiki \\
\hline
\end{tabular}


imum offline to deal with existing problems in the regions of low bandwidth and minimum Internet access. For example, an interactive exercise can be totally done online, as well as it can be done offline, but only solutions can be submitted online for grading. As shown in Table 3, the video lectures (C16) and audio lectures (C18) remain online in the proposed model to keep the MOOCs major features intact. The major advantage of the proposed model is that, there is no need to change the existing learner infrastructure, rather only the MOOC provider need to realign or rearrange the course materials and assessment methods so that they are accessible completely irrespective of bandwidth limitations.

Table 2. General assessment methods in existing MOOCs

\begin{tabular}{|l|l|}
\hline Ref. Index & \multicolumn{1}{|c|}{ Content Details } \\
\hline A1 & Multiple choice questions(MCQ's) with feedback \\
\hline A2 & Multiple choice questions (MCQ) without feedback \\
\hline A3 & Interactive quizzes \\
\hline A4 & Checkbox questions with feedback \\
\hline A5 & Checkbox questions without feedback \\
\hline A6 & Textbox filling questions with feedback \\
\hline A7 & Textbox filling questions without feedback \\
\hline A8 & Drag and drop questions with feedback \\
\hline A9 & Drag and drop questions without feedback \\
\hline A10 & Selecting proper sequence questions with feedback \\
\hline A11 & Selecting proper sequence questions without feedback \\
\hline A12 & Auto-graded assignments with feedback \\
\hline A13 & Auto-graded assignments without feedback \\
\hline A14 & Simulation based questions \\
\hline A15 & Interactive assignments \\
\hline A16 & Homework assignments \\
\hline A17 & Peer-graded assignments \\
\hline A18 & Self-assessment/graded questions \\
\hline A19 & E-portfolios \\
\hline
\end{tabular}

Table 3. Summary of MOOCs content and assessment accessibility methods in the current and the proposed model

\begin{tabular}{|c|c|c|}
\hline Accessibility & Current Model & Proposed Model \\
\hline \multirow{4}{*}{ Online } & $\mathrm{C} 1, \mathrm{C} 2, \mathrm{C} 3, \mathrm{C} 4, \mathrm{C} 5, \mathrm{C} 6, \mathrm{C} 9, \mathrm{C} 11$, & \\
& $\mathrm{C} 12, \mathrm{C} 13, \mathrm{C} 15, \mathrm{C} 16, \mathrm{C} 17, \mathrm{C} 18$, & $\mathrm{C} 11, \mathrm{C} 15, \mathrm{C} 16, \mathrm{C} 18, \mathrm{C} 21, \mathrm{C} 23$, \\
& $\mathrm{C} 19, \mathrm{C} 20, \mathrm{C} 21, \mathrm{C} 23, \mathrm{C} 24, \mathrm{C} 25$, & $\mathrm{C} 25, \mathrm{~A} 1, \mathrm{~A} 3, \mathrm{~A} 4, \mathrm{~A} 6, \mathrm{~A} 8, \mathrm{~A} 10$, \\
& $\mathrm{A} 1, \mathrm{~A} 2, \mathrm{~A} 3, \mathrm{~A} 4, \mathrm{~A} 5, \mathrm{~A} 6, \mathrm{~A} 7, \mathrm{~A} 8$, \\
$\mathrm{A} 10, \mathrm{~A} 11, \mathrm{~A} 12, \mathrm{~A} 13, \mathrm{~A} 14, \mathrm{~A} 16, \mathrm{~A} 17, \mathrm{~A} 18$ & \\
\hline \multirow{2}{*}{ Offline } & $\mathrm{C} 7, \mathrm{C} 8, \mathrm{C} 10, \mathrm{C} 14, \mathrm{C} 22$ & $\mathrm{C} 1, \mathrm{C} 2, \mathrm{C} 3, \mathrm{C} 4, \mathrm{C} 5, \mathrm{C} 6, \mathrm{C} 9, \mathrm{C} 13, \mathrm{C} 17$, \\
& $\mathrm{C} 7, \mathrm{C} 8, \mathrm{C} 10, \mathrm{C} 14, \mathrm{C} 20, \mathrm{C} 24, \mathrm{~A} 2, \mathrm{~A} 5, \mathrm{~A} 7, \mathrm{~A} 9, \mathrm{~A} 11$ \\
\hline \multirow{2}{*}{ Offline and Online } & $\mathrm{C} 22, \mathrm{~A} 15, \mathrm{~A} 19$ & $\mathrm{C} 7, \mathrm{C} 8, \mathrm{C} 10, \mathrm{C} 12, \mathrm{C} 14, \mathrm{C} 22, \mathrm{~A} 15, \mathrm{~A} 19$ \\
\hline
\end{tabular}




\section{Conclusion}

The existing MOOCs are considered as replacement for traditional classroom settings. However, in practice they fail to reach the enthusiastic learners with existing infrastructure challenges. Even though, MOOC trend is gaining popular attention around the world, less focus has been paid towards problems faced by the learners in developing regions. As the current model of MOOC is highly suitable for learning environments with better Internet infrastructure, considering bandwidth limitations existing in the developing countries, there is a need to align the MOOC contents suitable for offline learning. Considerable research is required to evaluate the $\mathrm{MOOC}$ contents which can be delivered online and studied offline. This way, more offline friendly courses can generate positive impact in low-bandwidth regions. Facilitating the proposed offline based solution not only reduces the resource usage, but also increases the possibilities of economical solutions towards reaching millions of online learners especially from developing countries.

\section{References}

[1] EDX At a Glance (2014). https://www.edx.org/sites/default/files/mediakit/file/media kit 10-21-2014.pdf

[2] NIIT \& edX partner to redefine online education to boost future-ready talent (2016). http://www.niit.com/india/training/newsroom/Pages/press-rel.aspx?ID=550

[3] Jordan, K. (2015). Massive Open Online Course Completion Rates Revisited: Assessment, Length and Attrition. The International Review of Research in Open and Distributed Learning, 16, 2:341-358. http://dx.doi.org/10.13140/RG.2.1.2119.6963

[4] Institute-wide Task Force on the Future of MIT Education, Final Report. July 28, 2014. http://web.mit.edu/future-report/TaskForceFinal_July28.pdf

[5] Population Reference Bureau (2013). World Population Data Sheet. http://www.prb.org/pdf13/2013-WPDS-infographic MED.pdf

[6] International Telecommunication Union. ICT Facts and Figures(2016). http://www.itu.int/en/ITU-D/Statistics/Documents/facts/ICTFactsFigures2016.pdf

[7] Emanuel, E. J. (2013). Online education: MOOCs taken by educated few. Nature 503 (correspondence), 342. http://dx.doi.org/10.1038/503342a

[8] Warusavitarana P. A., et al (2014). MOOC: a higher education game changer in developing countries. In Rhetoric and Reality: Critical perspectives on educational technology. Proceedings ascilite, B. Hegarty, J. McDonald, and SK Loke (eds.), Dunedin, New Zealand, pp 359-366.

[9] Oyo, B., \& Kalema, B.M. (2014). Massive Open Online Courses for Africa by Africa. 2014. The International Review of Research in Open and Distributed Learning, 15(6),1-13 http://dx.doi.org/10.19173/irrodl.v15i6.1889

[10] Arslan, F., Bagachi, K. \& Ryu, S.E. A Preliminary Evaluation of the Determinants of Certification Success in MOOCs: A Multi-level Study. 21st Americas Conference on Information Systems, 2015, Puerto Rico. pp 1-13.

[11] Liyanagunawardena, T. et al (2013). The impact and reach of MOOCs: a developing countries' perspective. eLearning Papers (33), ISSN 1887-1542. http://centaur.reading.ac.uk/32452/ 
[12] Murugesan, R. , Nobes, A., \& Wild, J.(2017). A MOOC approach for training researchers in developing countries. Open Praxis, 9(1): 45-57. https://doi.org/10.5944/openpraxis.9.1.476

[13] Bali, M. (2014). MOOC Pedagogy: Gleaning Good Practice from Existing MOOCs. MERLOT Journal of Online Learning and Teaching, 10(1): 44-56.

[14] Castillo, N. M., Lee, J., Zahra, F. T., \& Wagner, D. A. (2015). MOOCS for development: Trends, challenges, and opportunities. Information Technologies \& International Development, 11(2): 35-42

[15] Rambe, P. \& Moeti, M. (2017). Disrupting and democratising higher education provision or entrenching academic elitism: towards a model of MOOCs adoption at African universities. Educational Technology Research and Development, 65(3): 631-651. https://doi.org/10.1007/s11423-016-9500-3

[16] Breslow, L. et al (2013). Studying Learning in the Worldwide Classroom Research into edX's First MOOC. Research and Practice in Assessment, 8, 13-25.

\section{$7 \quad$ Author}

Laxmisha Rai received Ph.D from Kyungpook National University, South Korea in 2008. He also worked as a Post-Doctoral Researcher at Soongsil University, South Korea. Currently, he is a Professor in the College of Electronics, Communication and Physics, Shandong University of Science and Technology, China. His research interests include software engineering, real-time systems, embedded systems, autonomous mobile robots, expert systems, wireless sensor networks, MOOC, and Bilingual Education. He has published over 50 research papers and currently serving as Associate Editor of IEEE Access Journal. He is a Senior Member of IEEE, and Member of ACM.

Article submitted 20 March 2018. Resubmitted 11 May 2018. Final acceptance 13 May 2018. Final version published as submitted by the author. 